\title{
Are Decision Makers Rational in Ambiguous Situations?
}

\author{
Amílcar Serrão \\ Associate Professor in Management Department Evora University, Largo dos Colegiais, Evora, \\ Portugal \\ aserrao@uevora.pt
}

\begin{abstract}
This research work analyzes human behavior in complex situations and explains how decisions makers act in ambiguous situations.

The objective of this research work is to study the sunk cost effect and the completion percentage effect of an investment project in a decision-making process. This research work uses a "retrospective rationality" approach to justify irrational behaviors such as the sunk cost effect, the completion percentage effect of an investment project and the irrational escalation since decision-makers are repeatedly affected by the decisions on past irreversible investments.
\end{abstract}

This research work evaluates three sunk cost levels, and three completion percentage levels of an investment project, besides three neutral situations in a business environment and a personal decision situation. Graduate students in three Portuguese Management Schools responded to the questionnaires.

Model results show that the value of resources invested is crucial for understanding the students' rational behavior, who participated in this research work. These results disclose statistical evidence that the information on sunk costs and completion percentage of an investment project determines human behavior under irrational escalation in ambiguous situations. As a consequence, decision makers have the opportunity to interpret their decisions, since the scenarios do not allow a unique definition of rational choice, it is not correct to judge the irrational decision makers that decide to continue to invest in ambiguous situations.

Keywords: Human Behavior, Sunk costs Effect, Completion Percentage Effect of an Investment Project, Irrational Escalation, Ambiguous Situations.

JEL Classification: C12, D80, G10

\section{INTRODUCTION}

This research work studies the sunk cost effect and completion percentage effect of an investment project in a decision-making process (Domingos, 2007; and, Silva, 2010). The "retrospective rationality" approach is applied to justify irrational behaviors such as the sunk cost effect, the completion percentage effect of an investment project and the irrational escalation since decisionmakers are repeatedly affected by the decisions on past irreversible investments (Ponte and Bonifacio, 2004).

Ambiguous situations are those in which there is a lack of meaning since there is no sufficient information to formulate a unique frame that helps us to interpret events and find probabilities (Cohen, March, and Olsen, 1972; March and Olsen, 1976; and, Hatch, 1997). This research work shows that the higher the ambiguity of the decision context, the more people will escalate and provide some data to sustain the incidence of the irrational escalation in a decision-making process. The problem statement is what factors determine the incidence of the irrational escalation in a decision process.

The overall objective is to describe the irrational escalation through the factors which determine their occurrence. This objective has three specific objectives. The first one is to verify the importance of the sunk cost effect on irrational escalation. The second one is to check the importance of the completion percentage effect of an investment project on irrational escalation. The last one is to analyze the effect of some factors on irrational escalation.

This article has the following chapters. The next one presents literature review. The third one explains the methodology. The fourth one describes the data and information. The fifth one analyzes and discusses results. The last one presents conclusions. 


\section{LITERATURE REVIEW}

Modern Finance Theory and Behavior Finance help us to understand the decision-making process. Modern Finance theory assumes that markets are perfectly stables, and decision makers are rational (McMahon, 2005; Statman, 1999; Rabin, 1998; Slovic, Fischhoff, and Lichtenstein, 1977; and, Thaler, 1999). Their predictions might not characterize decision makers' behavior. Research works have shown there exist violations of their assumptions.

Behavior Finance analyzes decision makers' behavior in financial situations considering the violations of rational choices and looking for understanding the psychology behind these alternatives. The understanding of the decision process has permitted to explain the judgment errors such as conjunction fallacy, escalation of commitment, commitment bias, base rate error, excessive optimism, illusion of control (McMahon, 2005; Tversky and Kahneman, 1981; Tversky and Kahneman, 1986; Rabin, 1998; and, Slovic, Fuschhoff, and Lichtenstein, 1977; and, Macaskill, and Hackenberg, 2012).

Sunk costs are retrospective costs already incurred, and cannot be recovered (Garrison,Noreen, and Brewer, 2012; Martin, 2002; Wang and Yang, 2001; Park, and Jang, 2014; and, Balasubramanian, Kalyanasundaram, and S, 2016). Modern Finance Theory considers that sunk costs are not relevant in a decision-making process. Sunk costs cannot be used to make decisions about future events. Only revenues and costs should be necessary to allocate resources (Atkinson etal., 2001; and Garrison, Noreen, and Brewer, 2012). We should ignore Sunk costs when decision makers choose among future alternatives.

Sunk costs do not only have an economic meaning, but they also have a psychological sense (Luther, 1992). If an investment project is almost completed and there are negative feedbacks, the tendency is to continue increasing investment (Keil, Mann, and Rai, 2000; and, Kelly, and Milkman, 2013). The commitment of decision maker for continuing with negative information produce uncertainties when objectives are reached.

Irrational escalation refers to a situation in which decision makers can make irrational decisions based upon rational decisions in the past or to justify actions already taken which depend on two critical variables (Keil, Truex, and Mixon, 1995; and, Staw, and Ross, 1989), that is, sunk cost effect and completion percentage effect of an investment project.The first one is the sunk cost effect on the value of resources already invested. In this case, the decision maker assumes a commitment to continue investing in an attempt to reverse the negative situation. The second one is the completion percentage effect of an investment project and means how much an investment project is close to being completed (Keil, Truex, and Mixon, 1995; and, Buxton, and Rivers, 2014).

Research studies have shown that the existence of personal responsibility increases sunk cost effect, and the non-existence decreases it, but it does not disappear. This statement is consistent with the Prospect Theory and, decision makers have difficulty in accepting a wrong decision and a mistaken when they make a choice. The closer is the completion of the project, the greater the desire to continue investing. The study of sunk cost effect and completion percentage effect of an investment project is necessary to understand their effects on irrational escalation (Domingos, 2007; Silva, 2010; and, Bonifacio and Ponte, 2006).

\section{METHODOLOGY}

This research work uses Domingos' and Silva's approaches, which use three different investment scenarios characterized by increasing levels of interpretability in each one of the questionnaires. We present one of these scenarios below:

"As the president of a company, you have invested 10 million Euros of the company's money into a research project. The purpose was to develop an electric car. When the project is $90 \%$ completed, another company begins marketing an electric car that is much faster and far more economical than the car your business could build. The question is: should you invest the last $10 \%$ of the research funds to finish your electric car?" (Scenario adapted from a study developed by Arkes and Blumer, 1985).

Statistical tests are used to verify whether variances are equal or different among to various questionnaires and to determine whether there are significant differences among their means, which 
require the hypotheses formulation and the use of the $t$-test for variance and the $t$ test for means and the Chi-square test for differences in two proportions (Levine, Stephan, Krehbiel, and, Berenson, 2008). The null hypotheses are the following:

$\mathrm{H}_{0}$ : the variance of the willingness of the respondents of the questionnaires $\mathrm{A}, \mathrm{B}, \mathrm{C}, \mathrm{AA}, \mathrm{BB}$ and $\mathrm{CC}$ is equal to the variance of the willingness of respondents of the questionnaires A.1, B.1, and C.1;

$\mathrm{H}_{0}$ : the mean of the willingness of the respondents of the $(\mathrm{A}, \mathrm{B}, \mathrm{C})$ or $(\mathrm{AA}, \mathrm{BB}$, and $\mathrm{CC}$ ) questionnaires is equal to the mean of the willingness of the respondents of the A.1, B.1,and C.1 questionnaires; and,

$\mathrm{H}_{0}$ : the observed frequency of the incidence of the irrational escalation of the respondents of the (A, $\mathrm{B}, \mathrm{C})$ or $(\mathrm{AA}, \mathrm{BB}$, and $\mathrm{CC}$ ) questionnaires is equal to the observed frequency of the incidence of the irrational escalation of the respondents of the A.1, B.1, and C.1 questionnaires. All tests use a 0.05 level of significance.

\section{DATA AND INFORMATION}

This research work uses four questionnaires to collect data and information. Threeof these questionnaires include a scenario and respondent's information such as sex, age, institution and graduate program. The respondent's information was adapted from the research works of Carpenter, Matthews and Brown (2005), Domingos (2007), and Silva (2010). Each one of these questionnaires includes a scenario, where the respondent assumes the role of the vice-president of a corporation, and he is responsible for a budget of ten million Euros to develop an electric car. In addition to these three types of questionnaires, it was also developed one questionnaire to capture the sunk cost effect on the resource allocation process involving a personal decision, so that we can assess whether the environment, in which the decision maker is inserted, interfere in their decisions (Tan and Yates, 1995). The participant has to choose to travel to the Azores (questionnaire I), and he paid 1,500.00 Euros, while the travel to Madeira (questionnaire II) was won in a contest show, that is, there was no payment. However, there is a perception that the travel to Madeira will be more fun. The neutral version (questionnaire II) does not have any value and the perception that the free travel will be more fun remains. The answer to this questionnaire is the choice between the travel to the Azores or Madeira.

Table1. Questionnaires Types

\begin{tabular}{|l|l|l|}
\hline Questionnaire Type & Scenarios & Information \\
\hline \% Completion & A & $90 \%$ completed \\
\hline & B & $50 \%$ completed \\
\hline & C & $10 \%$ completed \\
\hline Sunk cost & AA & 9 million invested \\
\hline & BB & 5 million invested \\
\hline Neutral & CC & 1 million invested \\
\hline & A.1 & No investment value \\
\hline & B.1 & No investment value \\
\hline Personal decisions & C.1 & No investment value \\
\hline Neutral & I & Paid holiday \\
\hline
\end{tabular}

Three hundred and twenty graduate students of three Portuguese Management Schools participated voluntarily in this research work (Grejo, Faia, and Abbas, 2015). The institutions were one University and two Polytechnic Institutes. Every participant was asked to respond to a random questionnaire (Table 1).

Table 2 presents the sampling distribution of the questionnaires.

This analysis of the data collected by sex shows that the sample has $44.6 \%$ of males and $55.4 \%$ of females. There are two age groups. The first one with age above 21 years old represents $41.6 \%$ of the sample, while the second one with age equal or under 21 years old is about $58.4 \%$ of the sample. The University and the two Polytechnic Institutes represent $48.5 \%$ and $51.5 \%$ of the sample. The Accounting and Finance graduate students and other graduate students in both institutions represent $49.5 \%$ and $50.5 \%$ of the sample, respectively. 
Table2. Sampling Distribution of Questionnaires

\begin{tabular}{|l|l|l|}
\hline Questionnaires & Sample & $\%$ \\
\hline A & 31 & 11.57 \\
\hline B & 27 & 10.07 \\
\hline C & 30 & 11.19 \\
\hline A.1 & 30 & 11.19 \\
\hline B.1 & 29 & 10.82 \\
\hline C.1 & 29 & 10.82 \\
\hline AA & 31 & 11.57 \\
\hline BB & 28 & 10.45 \\
\hline CC & 28 & 10.45 \\
\hline Subtotal & 263 & 82.19 \\
\hline I & 28 & 49.12 \\
\hline II & 29 & 50.88 \\
\hline Subtotal & 57 & 17.81 \\
\hline Total & 320 & 100.00 \\
\hline
\end{tabular}

Source: Author's results

\section{RESUltS}

This chapter has three sections. The first one analyzes the sunk cost effect of an investment project on irrational escalation. The second one discusses the completion percentage effect of an investment project on irrational escalation. The last one describes the sunk cost effect in the resource allocation process involving personal decisions.

\subsection{The Sunk Cost Effect of an Investment Project on Irrational Escalation}

The statistical analysis of sunk cost effect by the median shows that the willingness of respondents to AA, BB and, CC scenarios is high because the values of median are not below 90\% (Table 3).

Table3. Sunk Cost Effect - Statistical Analysis

\begin{tabular}{|l|l|l|l|l|}
\hline Questionnaires & n & Mean & Median & $\sigma$ \\
\hline AA & 31 & 67.61 & 100 & 7.57 \\
\hline BB & 28 & 71.14 & 90 & 7.07 \\
\hline CC & 28 & 72.32 & 100 & 8.19 \\
\hline A.1 & 30 & 52.21 & 50 & 8.19 \\
\hline B.1 & 29 & 53.42 & 60 & 7.82 \\
\hline C.1 & 29 & 61.03 & 80 & 7.82 \\
\hline
\end{tabular}

Source: Author's results

Note: $\sigma$ - Standard Deviation

The willingness of respondents for A.1, B.1, and C.1 scenarios decreases and the median values are below $90 \%$, and the investment value is not known. There is evidence that the disclosure of the investment value determines the incidence of the sunk cost effect. Although the median values are high, above 50, and, the statistical dispersion of data is not high. Furthermore, the median values are not gathered close to the mean, except A.1 and B.1 cases. The statistical dispersion can be justified by the high incidence of extreme values (0 to 100), with few common responses. On the sunk cost effect, we can see that the mean values are high. This situation indicates the willingness of respondents to continue investing in a project that has negative feedback. The means values of the neutral questionnaires show that the higher the value of resources to be used in an investment project, the greater the willingness of decision makers to invest in the development of the investment project.

Table4. Sunk Cost Effect - The t test for mean

\begin{tabular}{|l|l|l|}
\hline Questionnaires & $\mathrm{t}$ & $\mathrm{p}$ \\
\hline AA X A.1 & -3.215 & 0.001 \\
\hline BB X B.1 & -3.843 & 0.000 \\
\hline CC X C.1 & -2.095 & 0.020 \\
\hline
\end{tabular}

Source: Author's results $\quad$ Note: $t$-test and p-value

\begin{tabular}{ll|l} 
International Journal of Managerial Studies and Research (IJMSR) & Page & 16
\end{tabular} 
We can see where the information of the value already invested, the average of responses was higher than that obtained in a neutral scenario. When no data are available for the value of resources already invested, the average of responses to investing is lower. We need to know whether these differences among means are significant. It was conducted the test for mean for a 0.05 significance level (Table 4). The test results show that the null hypothesis that the means values are equal is rejected. Therefore, the value of resources already invested determines the incidence of the sunk cost effect, because the differences among the means are significant. The information of sunk costs is relevant in the incidence on irrational escalation since it was found significant differences among means.

Table5. Sunk Cost Effect - Frequencies

\begin{tabular}{|l|l|l|l|l|l|}
\hline Respondents & \multicolumn{2}{l}{} & $>50$ & $\geq 50$ & \\
\hline $\mathrm{n}$ & & yes & $\%$ & yes & $\%$ \\
\hline AA & 31 & 21 & 66.34 & 23 & 75.34 \\
\hline BB & 28 & 18 & 70.51 & 22 & 79.04 \\
\hline CC & 28 & 20 & 72.78 & 21 & 76.55 \\
\hline A. 1 & 30 & 14 & 47.76 & 18 & 61.43 \\
\hline B. 1 & 29 & 15 & 51.31 & 18 & 62.49 \\
\hline C. 1 & 29 & 17 & 57.08 & 21 & 71.21 \\
\hline
\end{tabular}

Source: Author's results

Regarding the impact of the sunk cost effect, the AA scenario, where 9 million euros were invested, $66 \%$ of people surveyed invest more resources, while the neutral A.1 scenario does not reach $50 \%$, as shown in Table 5. In this case, the disclosure of the information of sunk cost proved to be significant in the incidence of the sunk cost effect.

The null hypothesis that the means values are equal is rejected. The results show that investment value is relevant in the incidence of the sunk cost effect. There are significant differences among means values.

Table6. Sunk Cost Effect - Analysis of Factors

\begin{tabular}{|l|l|l|l|l|}
\hline Questionnaires & Sex & Age & Institution & Program \\
\hline AA & $\chi^{2}=0.128$ & $\chi^{2}=2.773$ & $\chi^{2}=0.312$ & $\chi^{2}=1.011$ \\
\hline & $\mathrm{t}=0.734$ & $\mathrm{t}=1.314$ & $\mathrm{t}=0.022$ & $\mathrm{t}=0.583$ \\
\hline $\mathrm{BB}$ & $\chi^{2}=0.363$ & $\chi^{2}=0.003$ & $\chi^{2}=2.362$ & $\chi^{2}=0.521$ \\
\hline & $\mathrm{t}=-0.315$ & $\mathrm{t}=0.143$ & $\mathrm{t}=2.032$ & $\mathrm{t}=1.342$ \\
\hline $\mathrm{CC}$ & $\chi^{2}=0.038$ & $\chi^{2}=0.367$ & $\chi^{2}=3.165$ & $\chi^{2}=0.051$ \\
\hline & $\mathrm{t}=-0.364$ & $\mathrm{t}=0.336$ & $\mathrm{t}=-1.332$ & $\mathrm{t}=0.375$ \\
\hline A.1 & $\chi^{2}=1.353$ & $\chi^{2}=0.174$ & $\chi^{2}=0.643$ & $\chi^{2}=0.001$ \\
\hline & $\mathrm{t}=-0.645$ & $\mathrm{t}=-0.197$ & $\mathrm{t}=-1.078$ & $\mathrm{t}=0.113$ \\
\hline B.1 & $\chi^{2}=0.191$ & $\chi^{2}=0.217$ & $\chi^{2}=1.017$ & $\chi^{2}=0.033$ \\
\hline & $\mathrm{t}=0.102$ & $\mathrm{t}=1.022$ & $\mathrm{t}=0.533$ & $\mathrm{t}=0.003$ \\
\hline C. 1 & $\chi^{2}=2.322$ & $\chi^{2}=4.521$ & $\chi^{2}=4.801$ & $\chi^{2}=5.013^{* * *}$ \\
\hline & $\mathrm{t}=-1.521$ & $\mathrm{t}=2.121$ & $\mathrm{t}=-1.346$ & $\mathrm{t}=2.235^{* * *}$ \\
\hline
\end{tabular}

Source: Author's results

We present the results of hypothesis testing for the factors in Table 6. These results show that there are no significant behavior differences between men and women in all kinds of questionnaires. The age and institution factors, only in the C.1 neutral scenario, are significant for the sample. Moreover, the accounting and financial graduate students show behavior different from other graduate students in the C.1 questionnaire used to capture the sunk cost effect.

\subsection{The Completion Percentage Effect of an Investment Project on Irrational Escalation}

The statistical analysis of completion percentage effect of an investment project by the median values shows that the willingness of respondents for $\mathrm{A}, \mathrm{B}$, and Cscenarios is high because their median values are not below $80 \%$ (Table 7). The A.1, B.1, and C.1 questionnaires, in which the information of completion percentage of an investment project is not presented, show that the willingness of the 
respondents is lower, except in the C.1 questionnaire with $80 \%$. The results show that the completion percentage effect of an investment project is above $60 \%$ which indicates a willingness of the respondents to continue investing in an investment project that has a scenario not favorable. The willingness increases when the project is over close to completion. The average of the responses for $90 \%$ of the investment project is higher than the 50\% case. TheA.1, B.1, and C.1 questionnaires show that the higher the value of resources to be invested, the greater the willingness of decision makers to invest in the analyzed investment project. When the completion percentage of an investment project was highlighted, the willingness of respondents to continue investingwas higher. This situation suggests that the completion percentage of an investment project is crucial for the incidence on irrational insistence.

Table7. Completion Percentage Effect - Statistical Analysis

\begin{tabular}{|l|l|l|l|l|}
\hline Questionnaires & n & Mean & Median & 年 \\
\hline A & 31 & 70.12 & 100 & 7.45 \\
\hline B & 27 & 66.35 & 80 & 6.41 \\
\hline C & 30 & 61.32 & 90 & 7.67 \\
\hline A.1 & 30 & 52.21 & 50 & 5.19 \\
\hline B.1 & 29 & 53.42 & 60 & 5.82 \\
\hline C.1 & 29 & 61.03 & 80 & 5.82 \\
\hline
\end{tabular}

Source: Author's results

Note: $\sigma$-Standard Deviation

Table8. Completion Percentage Effect - The t test for mean

\begin{tabular}{|l|l|l|}
\hline Questionnaires & $\mathrm{t}$ & $\mathrm{p}$ \\
\hline A X A.1 & 4.162 & 0.001 \\
\hline B X B.1 & 2.904 & 0.000 \\
\hline C X C.1 & 0.055 & 0.651 \\
\hline
\end{tabular}

Source: Author's results

Note: $t$-test and $p$-value

The null hypothesis that the means values are equal is rejected except to the CxC.1 questionnaires (Table 8). The completion percentage of $90 \%$ and $50 \%$ for an investment project is relevant in the incidence on irrational escalation, and it was found significant differences among their means values.

Table9. Completion Percentage Effect - Frequencies

\begin{tabular}{|l|l|l|l|l|l|}
\hline \multicolumn{2}{|l|}{ Participants } & $>50$ & $\geq 50$ \\
\hline \multicolumn{2}{|c|}{$\mathrm{n}$} & yes & $\%$ & yes & $\%$ \\
\hline A & 31 & 22 & 70.11 & 24 & 79.23 \\
\hline B & 28 & 18 & 65.03 & 22 & 78.48 \\
\hline C & 28 & 16 & 58.54 & 19 & 69.37 \\
\hline A.1 & 30 & 14 & 47.76 & 18 & 61.43 \\
\hline B.1 & 29 & 15 & 51.31 & 18 & 62.49 \\
\hline C. 1 & 29 & 17 & 57.08 & 21 & 71.21 \\
\hline
\end{tabular}

Source: Author's results

The frequency analysis for irrational insistence is displayed in Table 9. This analysis shows that $70 \%$ of the sample continues investing in the A questionnaire, while only $48 \%$ would continue investing in the A.1 scenario. The completion percentage of an investment project is significant in the incidence on irrational escalation, and it was rejected for the 5\% significant level. When the project is only $10 \%$ complete, $58.5 \%$ acts irrationally, and the C.1 questionnaire represents $53.4 \%$ of the sample. The disclosure of the completion percentage of $10 \%$ for an investment project does not have any effect on the incidence of irrational insistence, and it was not rejected for the 0.05 significant level.

We present the results of hypothesis testing performed for the analysis of factors in this research work in Table 10. These results show that no significant behavioral differences between men and women in all types of questionnaires. The age and institution factors were only significant for the sample in the C.1 scenario. Finally, graduate students in accounting and finance behave differently from other graduate students in the C.1 questionnaire used to capture the completion percentage effect of an investment project. 
Are Decision Makers Rational in Ambiguous Situations?

Table10. Completion Percentage Effect - Analysis of Factors

\begin{tabular}{|l|l|l|l|l|}
\hline Questionnaires & Sex & Age & Institution & Program \\
\hline $\mathrm{A}$ & $\chi^{2}=2.353$ & $\chi^{2}=1.015$ & $\chi^{2}=0.292$ & $\chi^{2}=1.133$ \\
\hline & $\mathrm{t}=-1.032$ & $\mathrm{t}=0.435$ & $\mathrm{t}=0.107$ & $\mathrm{t}=0.442$ \\
\hline $\mathrm{B}$ & $\chi^{2}=0.212$ & $\chi^{2}=4.013^{* *}$ & $\chi^{2}=1.471$ & $\chi^{2}=0.098$ \\
\hline $\mathrm{C}$ & $\mathrm{t}=0.078$ & $\mathrm{t}=-2.003^{* *}$ & $\mathrm{t}=1.153$ & $\mathrm{t}=0.687$ \\
\hline & $\chi^{2}=1.255$ & $\chi^{2}=1.124$ & $\chi^{2}=1.463$ & $\chi^{2}=0.167$ \\
\hline A.1 & $\mathrm{t}=1.177$ & $\mathrm{t}=-0.311$ & $\mathrm{t}=0.691$ & $\mathrm{t}=0.146$ \\
\hline & $\chi^{2}=1.353$ & $\chi^{2}=0.174$ & $\chi^{2}=0.643$ & $\chi^{2}=0.001$ \\
\hline B.1 & $\mathrm{t}=-0.645$ & $\mathrm{t}=-0.197$ & $\mathrm{t}=-1.078$ & $\mathrm{t}=0.113$ \\
\hline & $\chi^{2}=0.191$ & $\chi^{2}=0.217$ & $\chi^{2}=1.017$ & $\chi^{2}=0.033$ \\
\hline C.1 & $\mathrm{t}=0.102$ & $\mathrm{t}=1.022$ & $\mathrm{t}=0.533$ & $\mathrm{t}=0.003$ \\
\hline & $\chi^{2}=2.214$ & $\chi^{2}=4.672^{* *}$ & $\chi^{2}=4.931$ & $\chi^{2}=4.289 * *$ \\
\hline
\end{tabular}

Source: Author's results

\subsection{The Sunk Cost Effect on Personal Decisions}

A questionnaire was used. Fifty-seven participants answer to the questionnaires (Table 2). Twentyeight participantsanswer to the questionnaire I, and $61.4 \%$ decided not to throw away the money that they already paid for the Azores holiday, although Madeira holiday was much more fun and desirable. Twenty-nine participants answer to the questionnaire II, and52.4\% decided to travel to the Azores because they had already paid for the Azores holiday package. We can conclude that the cost of 1500 Euros does not have influence in the irrational escalation. 37\% of the University students decided to travel to the Azores, while 52\% of Polytechnic students decided to travel to the Azores. Polytechnic students are more sensitive to irrational escalation than University students.

\section{Conclusions}

The Modern Financial Theory states that sunk costs should not be considered in the decision-making process. This situation does not happen in real life, and decision makers have a different behavior.

Model results confirm the sunk cost effect and the percentage completion effect of an investment project on the incidence of irrational escalation. The sunk cost effect (1, 5 and 9 million Euros) have an impact on the incidence of irrational escalation. The completion percentage of $50 \%$ and $90 \%$ of an investment project has an impact on the incidence of irrational escalation.

The analysis of factors shows that females are more sensitive than males, as well as the graduate students in Accounting and Finance, Polytechnic Institutes students and, students with age below 21 years old. These results help us to reinterpret the irrational escalation since the scenarios used to analyze such behavior were made in ambiguous situations. As a consequence, decisions makers can interpret the decision scenarios in different ways since the scenarios do not allow a unique definition of rational choice it is not correct to judge necessarily irrational decision makers that decide to continue investing in ambiguous situations. Some insight that ambiguity influences a constructive willingness to commit further resources to ongoing projects despite negative feedbacks is found in the scenarios we have done to analyze the relationship of sunk cost effect and completion percentage effect of an investment project on irrational escalation.

Further research should be done how sunk cost and completion percentage of an investment project affect irrational escalation, using more robust quantitative approaches and a more theoretical base.

\section{REFERENCES}

Arkes, H and Blumer, C., 1985. The Psychology of Sunk Costs. Organizational Behavior and Human Decision Processes, Science Direct, v. 35, n. 1, p. 124 - 140.

Atkinson, A., Banker, R., Kaplan, R. and Young, S., 2001. Management Accounting. $3^{\text {rd }}$ Edition, Pearson Education, New York. 
Bonifacio, M.,and Ponte, D., 2006. Irrational Perseverant or Unrecoverable Optimist? A Normative Reading of Sunk Cost Affected Behaviors. ITC - Centre for Scientific and Technological Research. Via Sommarie, 18. Povo, Italy.

Balasubramanian, P., Kalyanasundaram, K., and S, A., 2016. Sunk Cost Fallacy: Effect of Situational Knowledge on Irrational Choices. SMS Varanasi, v. VIII, n. 2, p. 98-103.

Buxton, M., and Rivers, R., 2014. Escalation of Commitment: The Effects of Magnitude of Loss, Monitoring and the Presence of an Alternative Investment. Can a Project 90\% Complete be Stopped. Journal of Accounting and Finance, 14(5), 72 -85.

Carpenter, J.,Mathews, P., and Brown, A., 2005. The determinants of Sunk Cost Sensitivity in Students. Middlebury College Working Paper Series, 2005. Access in http://community. middlebury.edu/ jcarpent/papers/DSCS\%20Final.pdf. June 13, 2016.

Cohen, M., March, J. G. and Olsen, J., 1972. A Garbage Can Model of Organizational Choice. Administrative Science Quarterly, 17, 1-25.

Domingos, N., 2007. Custos Perdidos e Insistência Irracional. Universidade de Brasília, Universidade Federal da Paraíba, Universidade Federal de Pernambuco e Universidade do Rio Grande do Norte, Programa Multi-Institucional e Inter-Regional de Pós-Graduação em Ciências Contábeis. Unpublished Thesis, 123 p, Brasília, Brasil.

Garrison, R., Noreen, E. and Brewer, P., 2012. Managerial Accounting. 14 ${ }^{\mathrm{a}}$ Edition, McGraw-Hill, New York.

Grejo, L, Faia, V., and Abbas, K., 2015. Evaluation of Sunk Cost Effect in Decision Making of Scholars in Accounting Sciences and Business Administration. RACEF - Revista de Administração, Contabilidade e Economia da Fundace, v. 6, n. 2, p. 64-79.

Hatch, M., 1997. Organization Theory: Modern, Symbolic, and Postmodern Perspectives.

Oxford University Press, London.

Keil, M., Truex, D. and Mixon, R., 1995. The Effects of Sunk Cost and Project Completion

on Information Technology Project Escalation. IEEE Transactions on Engineering Management, IEEE Engineering Management Society, v.42, n. 4, p. 372-381.

Keil, M., Mann, J. and Rai, A., 2000. Why Software Projects Escalates: An Empirical Analysis and Test of Four Theoretical Models. MIS Quarterly, v. 24, n. 4, p. 631 - 664.

Levine, D., Stephan, D., Krehbiel, T. and Berenson, M., 2008. Statistical for Managers: Using Microsoft Excel, Fifth Edition, Published by Pearson Hall, New Jersey.

Kelly, T. and Milkman, K., 2013. "Escalation of commitment." In E. Kessler (Ed.), Encyclopedia of management theory. (pp. 257-260). Thousand Oaks, CA: SAGE Publications.

Luther, R., 1992. Fixed Costs and Sunk Costs in Decision-Making. Management Accounting, v. 70, n. 1, p. $37-42$.

Macaskill, A. and Hackenberg, T., 2012. Providing a Reinforcement History that Reduces the Sunk Cost Effect. Behavioral Processes. v. 89, n. 3, p. 212-218.

Martin, S., 2002. Sunk Cost and Entry. Review of Industrial Organization, v. 20, n. 4, p. 291 - 304.

March, J. and Olsen, J., 1976. Ambiguity and choice in organizations. Bergen.

McMahon, R, 2005. Behavioral finance: A Background Briefing. Research. Paper Series, 1, 1-36. Access in:〈http://www.flinders.edu.au/sabs/business/research/papers/05-9.pdf >. June 13, 2016.

Park, J.,and Jang, S., 2014. Sunk Costs and Travel Cancellation: Focusing on Temporal Cost. Tourism Management. v. 40, p. 425-435.

Ponte, D. and Bonifacio, M., 2004. "Constructive rationality: a positive account of the irrational escalation. Paper presented at the 11-TH International Conference On The Foundations \& Applications of Utility, Risk and Decision Theory (FUR XI), Paris.

Rabin, M., 1998. Psychology and economics. Journal of Economic Literature,v. 36, n. 1, p. 11 - 46.

Silva, C.,and Domingos, N., 2010. Sunk Cost e Insistência Irrational: O Comportamento face às Decisões de Alocação de Recursos. ASAA - Advances in Scientific and Applied Accounting, v.3, n.1, p.41-64.

Slovic, P., Fischhoff, B. and Lichtenstein, S., 1977. Behavioral decision theory. Annual Review of Psychology, Annual Review, v. 28, p. 1 - 39. 
Statman, M., 1999. Behavioral Finance: Past Battles and Future Engagements. Financial Analysts Journal, v. 55, n. 6, p. 18 - 27.

Staw, B. and Ross, J., 1989. Understanding behavior in escalation situations. Science. 246.

Tan, H., Yates, J., 1995. Sunk Cost Effects: The Influence of Instruction and Future Return Estimates. Organizational Behavior and Human Decision Processes, v. 63, p. 311 - 319.

Thaler, R., 1999. The End of Behavioral Finance. Financial Analyst Journal,v. 55, n.6, p. 12 - 17.

Tversky, A. and Kahneman, D., 1981. The Framing of Decisions and the Psychology of Choice. Science, v. 211, n. 4481, p. 453 - 458.

Tversky, A. and Kahneman, D., 1986. Rational Choice and the Framing of Decisions. Journal of Business, v. 59 , n. 4, p. $251-278$.

Wang, X. and Yang, B., 2001. Fixed and Sunk Costs Revisited. Journal of Economic Education, v. 32, n. 2, p. $178-185$.

\section{AUTHOR'S BIOGRAPHY}

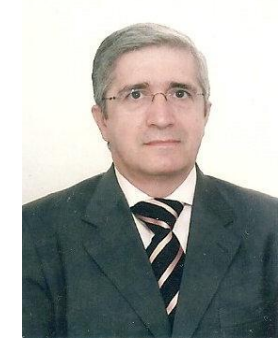

Amílcar Serrão, is Associate Professor at Evora University (Management Department), Evora (Portugal) where he has taught Operations Research, Decisions Models and Research Methodology for more twenty years. He is a $\mathrm{PhD}$ from Purdue University (West Lafayette, Indiana, USA, 1988). His works are essentially related to Mathematical Programming, Metaheuristics, Risk, Uncertainty and Ambiguity and Applied Financial and Economics Studies. 